\title{
Inositol-6 phosphate inhibits the mTOR pathway and induces autophagy-mediated death in HT-29 colon cancer cells
}

\author{
Ashok Kumar Pandurangan ${ }^{1,2}$, Salmiah Ismail'2, Norhaizan Mohd Esa², Murugan A. Munusamy³
}

\author{
${ }^{1}$ Department of Pharmacology, Faculty of Medicine, University of Malaya, Kuala Lumpur, \\ Malaysia \\ ${ }^{2}$ Department of Nutrition and Dietetics, Faculty of Medicine and Health Sciences, \\ Universiti Putra Malaysia, Serdang, Selangor, Malaysia \\ ${ }^{3}$ Department of Botany and Microbiology, College of Science, King Saud University, \\ Riyadh, Saudi Arabia
}

Submitted: 27 September 2016

Accepted: 12 January 2017

Arch Med Sci 2018; 14, 6: 1281-1288

DOI: https://doi.org/10.5114/aoms.2018.76935

Copyright $\odot 2018$ Termedia \& Banach

\section{Abstract}

Introduction: Colorectal cancer (CRC) is common, with a worldwide incidence estimated at more than 1 million cases annually. Therefore, the search for agents for CRC treatment is highly warranted. Inositol-6 phosphate (IP $\left.)_{6}\right)$ is enriched in rice bran and possesses many beneficial effects. In the present study the effect of IP6 on autophagy-mediated death by modulating the mTOR pathway in HT-29 colon cancer cells was studied.

Material and methods: Autophagy was assessed by acridine orange (AO) staining, transmission electron microscopy, and western blotting to detect LC3-II and Beclin 1. Akt/mTOR signaling protein expression was also analyzed by western blotting. Apoptosis was analyzed by annexin $V$ staining.

Results: Incubation of cells with $\mathrm{IP}_{6}$ resulted in downregulation of the $\mathrm{p}$-Akt at $3 \mathrm{~h}$. Along with that confocal microscopic analysis of $p-A K T, I_{6}$ administration resulted that a diminished expression of $\mathrm{p}$-Akt. mTOR pathway regulates autophagy and incubation with IP6 to HT-29 cells showed decreased expression of p-70S6Kinase, 4-EBP-1 in a time-dependent manner. Inositol-6 phosphate $(10 \mu \mathrm{g} / \mathrm{ml}, 24$ and $48 \mathrm{~h})$ induced autophagic vesicles, as confirmed by AO staining and transmission electron microscopy. We also found increased expression of LC3-II and Beclin 1 in a time-dependent manner after incubation with $\mathrm{IP}_{6}$. Furthermore, $\mathrm{IP}_{6}$ induced apoptosis, as revealed by annexin $\mathrm{V}$ staining.

Conclusions: Our results clearly indicate that IP6 induces autophagy by inhibiting the Akt/mTOR pathway.

Key words: inositol-6-phosphate, colorectal cancer, autophagy, mammalian target of rapamycin, apoptosis.

\section{Introduction}

Colorectal cancer (CRC) is common, with a worldwide incidence estimated at more than 1 million cases annually. Surgery remains the most effective curative treatment for CRC, but the risk of recurrence is high. Only $70 \%$ of cases are resectable, of which $75 \%$ are curable $[1,2]$. Thus, many patients receive adjuvant chemotherapy. Therefore, the search for chemotherapeutic agents for the treatment of CRC is highly

\author{
Corresponding author: \\ Norhaizan Mohd Esa PhD \\ Department of Nutrition \\ and Dietetics \\ Faculty of Medicine \\ and Health Sciences \\ Universiti Putra Malaysia \\ 43400 Serdang \\ Selangor, Malaysia \\ Phone: +603 89472427 \\ Fax: +603 89426769 \\ E-mail: nhaizan@upm.edu.my
}


warranted $[3,4]$. Many natural products can act as strong chemopreventive/therapeutic agents against CRC [5-8].

Inositol-6 phosphate $\left(\mathrm{IP}_{6}\right)$ is a simple ringed carbohydrate with six phosphate groups attached to each carbon. It is a major form of phosphorylated inositol present in food, constituting 1-5\% by weight of most cereals, nuts, oilseed, legumes, and grains. Inositol 6 phosphate, which occurs at 9.5-14.5\% by weight in rice bran, possesses various health benefits [9]. Both in vivo and in vitro experiments provide convincing evidence for the anti-carcinogenic effects of $\mathrm{IP}_{6}[10]$. Our own studies have shown that $\mathrm{IP}_{6}$ is effective against azoxymethane-induced CRC. It reduces the incidence of aberrant crypt foci and tumor formation [11]. It inhibits cell proliferation, arrests the cell cycle at the $\mathrm{G}_{2} \mathrm{M}$ phase, and induces apoptosis in hepatocellular carcinoma $[12,13]$.

Mammalian target of rapamycin (mTOR) is a vital signaling pathway involved in many cellular processes. It regulates many intracellular signaling molecules to provide energy resources to the cell. The involvement of mTOR signaling in CRC is well known. Similarly, the inhibition of mTOR signaling leads to the inhibition of CRC cell growth in vitro and adenoma formation in vivo [14-16]. Autophagy is a physiological process that allows the degradation of cytoplasmic contents, including unfolded proteins and membranous organelles, under certain stress conditions. This serves as a temporary survival mechanism [17]. mTOR1 is oncogenic and facilitates intracellular signaling for the translation of proteins required by the cell; it is also used by cancer cells for survival and growth. mTOR1 is a negative regulator of autophagy via binding to the Atg13-ULK1/2-FIP200 complex, phosphorylation of the complex components, and inhibition of autophagy. Nutrient deprivation results in the release of $\mathrm{mTOR} 1$ and dephosphorylation of ULK1/2 and Atg13 and hence facilitates the activation of autophagy [16]. Inositol 6 phosphate is considered a potent chemotherapeutic agent, and the mechanism of killing HT-29 human colon cancer cells is still not clear. We hypothesized that $\mathrm{IP}_{6}$ inhibits $\mathrm{mTOR}$ signaling, leading to the activation of autophagy-mediated death in HT-29 colon cancer cells.

\section{Material and methods}

\section{Cell culture}

The human colorectal cancer cell line HT-29 was purchased from the American Type Culture Collection (ATCC) (Manassas, VA, USA) and the cells were grown in Dulbecco's Modified Eagle Medium with the following supplements: $10 \%(\mathrm{v} / \mathrm{v})$ fetal bovine serum, $100 \mathrm{IU} / \mathrm{ml}$ penicillin, and $100 \mu \mathrm{g} / \mathrm{ml}$ streptomycin. Cells were grown in a sterile cell culture flask at $37^{\circ} \mathrm{C}$ in the presence of $5 \%$ carbon dioxide $\left(\mathrm{CO}_{2}\right)$.

\section{Cell viability assay}

Cells were seeded and cultured with various doses of $\mathrm{PP}_{6}(2.5-20 \mu \mathrm{g} / \mathrm{ml})$ for $24 \mathrm{~h}$. Culture media were replaced with $0.05 \%$ MTT solution and incubated at $37^{\circ} \mathrm{C}$ for $2 \mathrm{~h}$. Dimethyl sulfoxide was added after the removal of the MTT solution. After a brief incubation period, the absorbance of the solution was measured using a microplate reader.

\section{Immunofluorescence}

Cells were grown to $60-70 \%$ confluence on glass coverslips in 6-well plates and treated with $\mathrm{IP}_{6}$ for $16 \mathrm{~h}$. After treatment, cells were washed with phosphate-buffered saline (PBS), fixed with acetone:methanol $\left(-20^{\circ} \mathrm{C}, 10 \mathrm{~min}\right)$, and blocked in $10 \%$ nonimmune goat serum (Sigma-Aldrich, St. Louis, MO, USA) for 1 h. LC3-II (NOVUS Biologicals, Littleton, CO, USA) antibody was applied ( $1 \mathrm{~h}$ ), followed by incubation (1 h) with Alexa Fluor 594 F(ab')2 fragment of goat anti-mouse IgG (Invitrogen, Carlsbad, CA, USA). Nuclei were stained with Hoechst. Then, the slides were assessed using a fluorescent microscope.

\section{Transmission electron microscopy}

Samples were prepared for transmission electron microscopy according to a published protocol [18]. Briefly, the cells were fixed in $2.5 \%$ glutaraldehyde in $0.1 \mathrm{M}$ phosphate buffer $(\mathrm{pH} 7.4)$ for 30 min, post-fixed in 1\% osmium tetroxide in the same buffer for $30 \mathrm{~min}$, dehydrated in graded ethanol, washed with propylene oxide, embedded in Epon, and then sectioned using an ultra-microtome at a thickness of $90 \mathrm{~nm}$. Thin sections were stained with 5\% uranyl acetate and 5\% lead citrate and then examined using a transmission electron microscope at $75 \mathrm{kV}$.

\section{Autophagy detection}

Autophagy is a lysosomal degradation pathway for cytoplasmic material. The acidic intracellular compartments were visualized by acridine orange (AO) staining. After incubation, cells were washed with PBS and stained with $1 \mathrm{mg} / \mathrm{ml}$ AO for $15 \mathrm{~min}$ at $37^{\circ} \mathrm{C}$. Subsequently, cells were washed and analyzed under an inverted fluorescent microscope. Fluorescence microscopy was performed using 490-nm band-pass blue excitation filters and a 515-nm long-pass barrier filter. Owing to differences in acidity, autophagic lysosomes appeared as orange/red fluorescent cytoplasmic vesicles, while the cytoplasm and nucleolus were green. 


\section{Determination of apoptosis}

by annexin V-FITC

HT-29 colon cancer cells were seeded in 96-well plates at $2 \times 10^{5}$ cells per well for $16 \mathrm{~h}$, treated with $10 \mu \mathrm{g} / \mathrm{ml} \mathrm{IP}$ or control, and incubated at $37^{\circ} \mathrm{C}$ for 24 and $48 \mathrm{~h}$. The harvested cells were labeled with a mixture of $1: 1$ ratio of annexin V-FITC $(20 \mu \mathrm{g} / \mathrm{ml})$ and propidium iodide $(50 \mu \mathrm{g} / \mathrm{ml})$ at $37^{\circ} \mathrm{C}$ for $30 \mathrm{~min}$ in darkness. Then, the cells were analyzed for the expression of annexin $\mathrm{V}$, using a high-throughput screening machine (Thermo Scientific, Waltham, MA, USA).

\section{Western blot analysis}

Western blot analysis was performed to detect mTOR pathway components (p70-S6K, Total p-70-S6 Kinase, p-4EBP1, and Total-4-EBP1) and autophagy markers (Beclin 1 and LC3-II) [19]. Cells were lysed in ice-cold, whole-cell lysis buffer. For cytoplasmic and nuclear extraction, cells were lysed in cytoplasmic lysis buffer and nuclei were pelleted and lysed in hypotonic buffer (30 min). The protein concentration was measured by the Bradford method. Lysates were separated by sodium dodecyl sulfate-polyacrylamide gel electrophoresis and transferred to a polyvinylidene difluoride membrane and blocked in 4\% nonfat milk with $0.3 \%$ Tween 20 . Antigen-antibody complexes were visualized by chemiluminescence.

\section{Transfection of LC-3 siRNA}

The LC3 SiRNA Kit was purchased from Santa Cruz Biotechnology (Santa Cruz, CA, USA) and used according to the instructions provided in the kit. HT-29 cells were seeded at a concentration of $2 \times 10^{5}$ cells $24 \mathrm{~h}$ prior to transfection in a 6 -well plate. After $24 \mathrm{~h}$, the medium was discarded and cells were washed three times with PBS. Fetal bovine serum-free medium with 5\% penicillin/streptomycin was added to the cells. Three transfection complexes were prepared (resulting in final concentrations of LC3 siRNA/ control siRNA of $0.5 \mu \mathrm{g} /$ well) $10 \mathrm{~min}$ before they were applied to the medium. The cells were treated with $100 \mu \mathrm{l}$ of a transfection complex. Cells were incubated for $6 \mathrm{~h}$ and supplemented with $1 \mathrm{ml}$ of normal growth medium containing 2 times the normal concentration of serum and antibiotics ( $2 \times$ normal growth medium), without removing the transfection mixture. The cells were incubated for an additional 18-24 $\mathrm{h}$ and the medium was aspirated and replaced with fresh $1 \times$ normal growth medium. These cells were used to identify the cell viability and to analyze the expression of LC3-II. Each experimental condition was repeated in triplicate.

\section{Statistical analysis}

At least 3 independent biological replicates were performed for all experiments. For western blots, one representative blot is shown in the Figures. Quantification was performed from 3 independent experiments and the results are expressed as means \pm SD. Statistical evaluations were performed by Student's $t$-test for pairwise comparisons. $P<0.05$ was considered statistically significant.

\section{Results}

\section{Inositol-6 phosphate is cytotoxic to HT-29 colon cancer cells}

Cell viability was analyzed by MTT assay. HT-29 colon cancer cells were treated with $\mathrm{IP}_{6}$ at various concentrations, i.e., $0,2.5,5,7.5,10,15$, and $20 \mu \mathrm{g} / \mathrm{ml}$, for $24 \mathrm{~h}$. We found that the $\mathrm{IC}_{50}$ was $10 \mu \mathrm{g} / \mathrm{ml}$ (Figure 1). Accordingly, subsequent experiments were performed using a concentration of $10 \mu \mathrm{g} / \mathrm{ml}$.

\section{Inositol-6 phosphate inhibits Akt signaling in HT-29 colon cancer cells}

The results of western blot analysis of Akt signaling are summarized in Figure 2. Administration of $\mathrm{IP}_{6}$ to HT-29 colon cancer cells at doses of 10 and $15 \mu \mathrm{g} / \mathrm{ml}$ for $3 \mathrm{~h}$ resulted in decreased expression of p-Akt compared to the control cells. We did not detect alterations in the expression of total-Akt. We further confirmed the expression of p-Akt in HT-29 colon cancer cells by immunofluorescence. We obtained results similar to those in the western blot analysis. Accordingly, we confirmed that $\mathrm{IP}_{6}$ inhibits the expression of $\mathrm{p}$-Akt in HT-29 colon cancer cells.

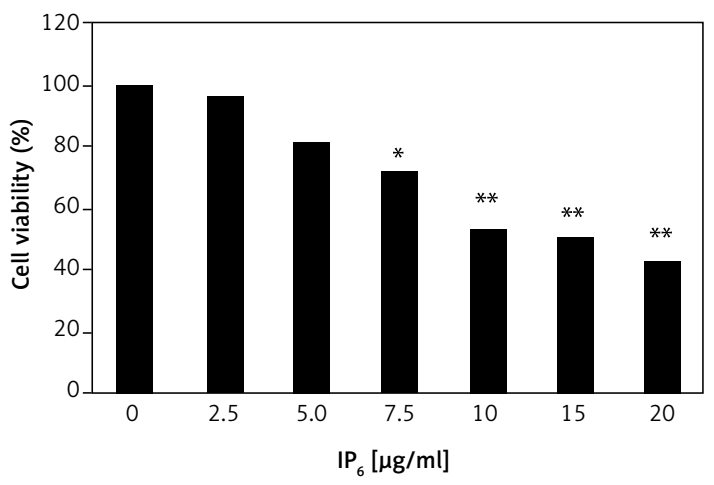

Figure 1. Inositol-6 phosphate $\left(\mathrm{IP}_{6}\right)$ is cytotoxic to HT-29 colon cancer cells. MTT cell viability assay. Inositol-6 phosphate showed $\mathrm{IC}_{50}$ at the dose of $10 \mu \mathrm{g} / \mathrm{ml}$. The detailed methods are described in the Material and methods section

Statistical significance compared with the untreated group. The statistical significance at ${ }^{*} p<0.05$ and ${ }^{* *} p<0.01$. 
A

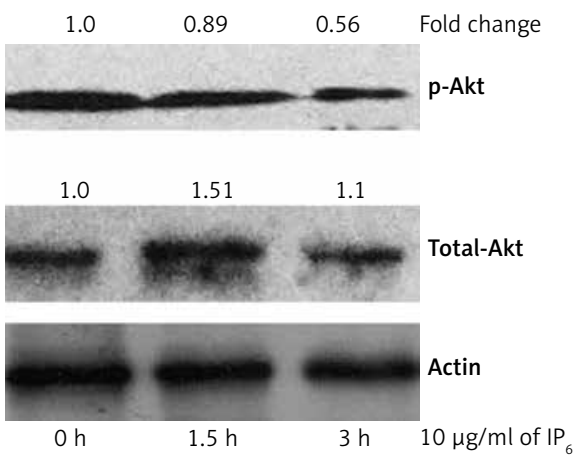

B
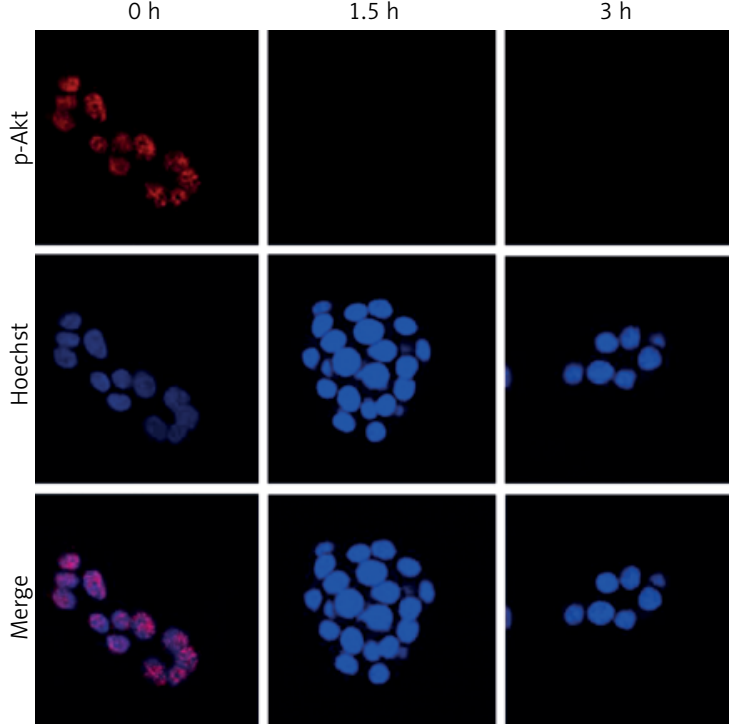
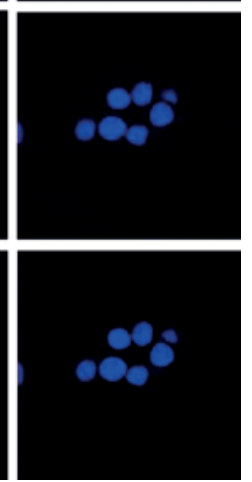

Figure 2. Inositol-6 phosphate (IP $)_{6}$ inhibits expression of p-Akt. A - Western blot analysis of p-Akt. Incubation of HT-29 cells with $\mathrm{IP}_{6}$ tends to suppress the expression of $\mathrm{p}$-Akt in less than $3 \mathrm{~h}$ compared with control cells. The quantification of western blots using Image J software was illustrated as fold change. B - Immunofluorescent analysis of p-Akt. The detailed methodology is described in the Material and Methods section (60x magnification). Similar results were obtained as those in the western blot analysis

A

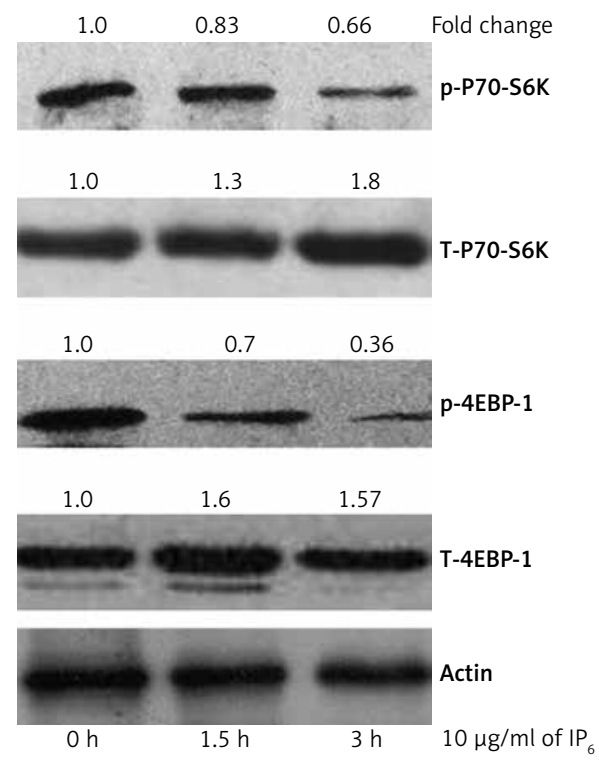

B
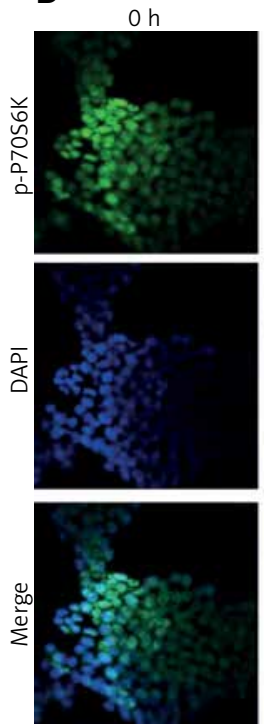
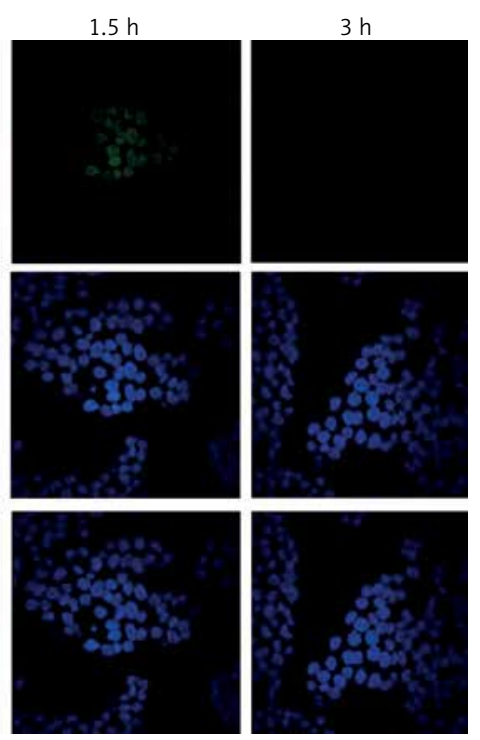

Figure 3. Inositol-6 phosphate (IP $)$ suppresses expression of downstream targets of mTOR signaling. A - Western blot analysis of p-Akt. Incubation of HT-29 cells with IP ${ }_{6}$ tends to suppress the expression of downstream targets of mTOR signaling, such as p70-S6K and p-4EBP1, in less than $3 \mathrm{~h}$. We also noted that the total forms of both p70-S6K and 4EBP1 were unaltered by treatment with $I_{6}$. The quantification of western blots using Image software was illustrated as fold change. B - Immunofluorescent analysis of p-p70S6K. The detailed methodology is described in the Material and methods section (40x magnification). Similar results were obtained as those in the western blot analysis

\section{Inositol-6 phosphate inhibits mTOR} signaling in HT-29 colon cancer cells

We next assessed the effect of $\mathrm{IP}_{6}$ on downstream targets of mTOR. It is well established that activated mTOR transmits its signal to activate P70-S6 kinase (S6K70) and negatively regulates eukaryotic translation initiation factor 4E-binding protein 1 (4EBP1), which binds to and inhibits eukaryotic translation initiation factor (elF) 4E [20]. Among several phosphorylation sites of P70-S6K, phosphorylation at $\mathrm{T}^{421 / 5424}$ is necessary for its activation and phosphorylation at $\mathrm{T}^{389}$ is required for 
$\mathrm{Oh}$

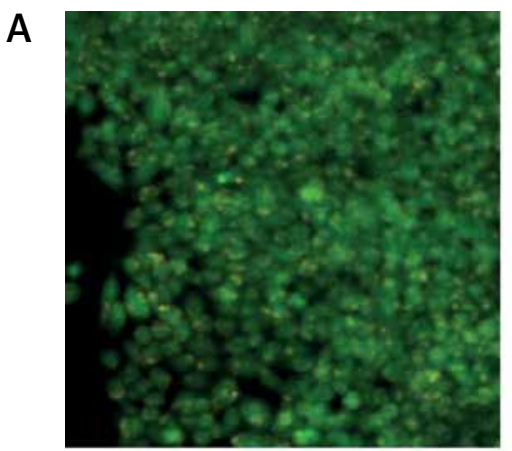

B

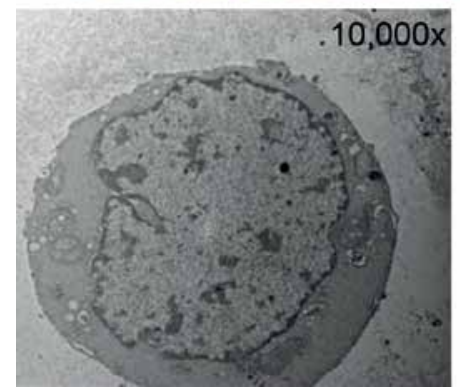

C
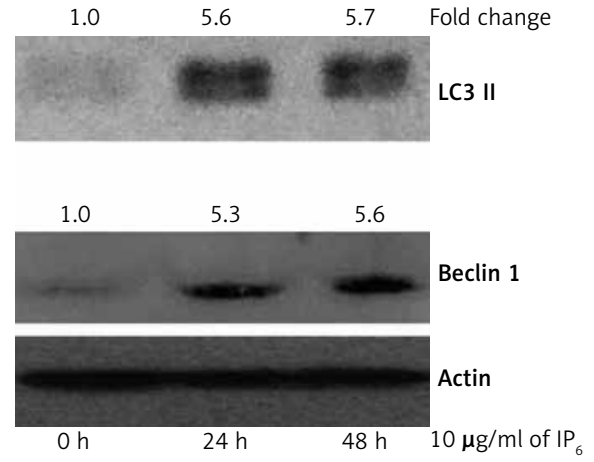

$24 \mathrm{~h}$
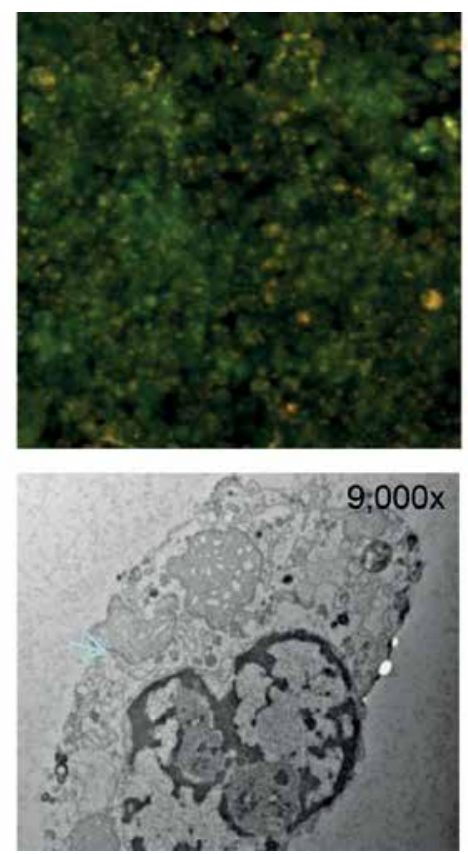

D
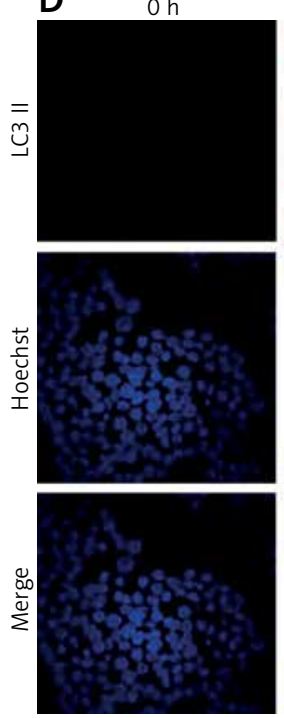

$48 \mathrm{~h}$
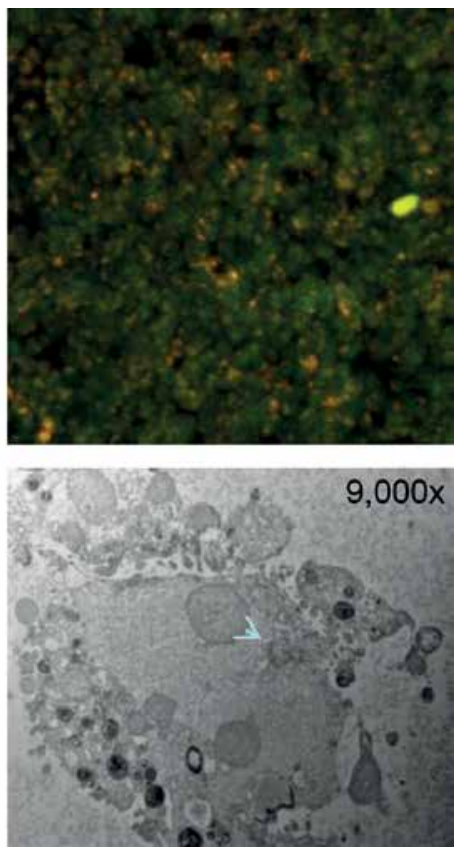

$24 \mathrm{~h}$
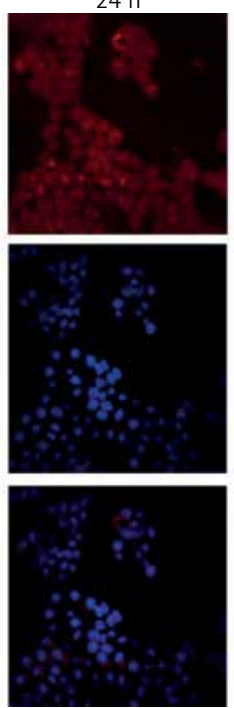

$48 \mathrm{~h}$
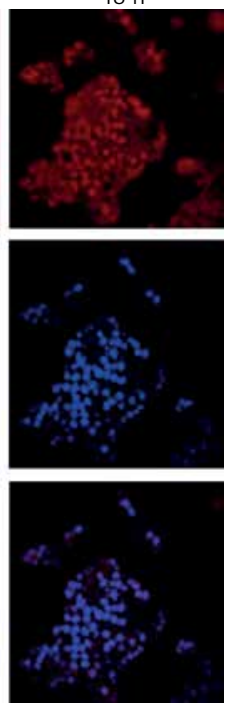

Figure 4. Inositol-6 phosphate (IP $)_{6}$ induces autophagy in HT-29 cells. A - Autophagy is a lysosomal degradation pathway for cytoplasmic material. The acidic intracellular compartments were visualized by acridine orange (AO) staining. Cells were treated with $10 \mu \mathrm{g} / \mathrm{ml} \mathrm{IP}$ for 24 and $48 \mathrm{~h}$. After incubation, cells were washed with phosphate-buffered saline and stained with $1 \mathrm{mg} / \mathrm{ml} \mathrm{AO}$ for $15 \mathrm{~min}$ at $37^{\circ} \mathrm{C}$. Subsequently, cells were washed and analyzed under an inverted fluorescent microscope. B - Transmission electron microscopic analysis of HT-29 cells after treatment with $\mathrm{IP}_{6}$. When $\mathrm{IP}_{6}$-treated cells were examined under a transmission electron microscope, doubleor multimembrane structures containing high-electron-density substances characteristic of autophagosomes and autolysosomes were present. Many autolysosomes were degraded in cells treated with $10 \mu \mathrm{g} / \mathrm{ml} \mathrm{IP}$ for 24 and $48 \mathrm{~h}$. C - Western blot analysis of LC3 and Beclin 1. Incubation of IP ${ }_{6}$ with HT-29 cells resulted in increased expression of LC3-II and Beclin 1. The quantification of western blots using ImageJ software was illustrated as fold change. D - Immunofluorescent analysis of LC3-II. The detailed methodology is described in the Material and methods section (40x magnification). Similar results were obtained as those observed in the western blot analysis

full kinase function [21]. The activation of S6K70 was significantly decreased after $\mathrm{IP}_{6}$ treatment (Figure $3 \mathrm{~A}$ ). The total P70-S6K and total 4EBP1 levels were unaltered in all groups. We thus found that $\mathrm{IP}_{6}$ significantly inhibits the mTOR pathway in HT-29 colon cancer cells.

\section{Inositol-6 phosphate induces autophagy} in HT-29 colon cancer cells

We determined the effect of $\mathrm{IP}_{6}$ on the formation of acidic vesicular organelles in HT-29 cells by fluorescent microscopy after staining with $\mathrm{AO}$. 
A

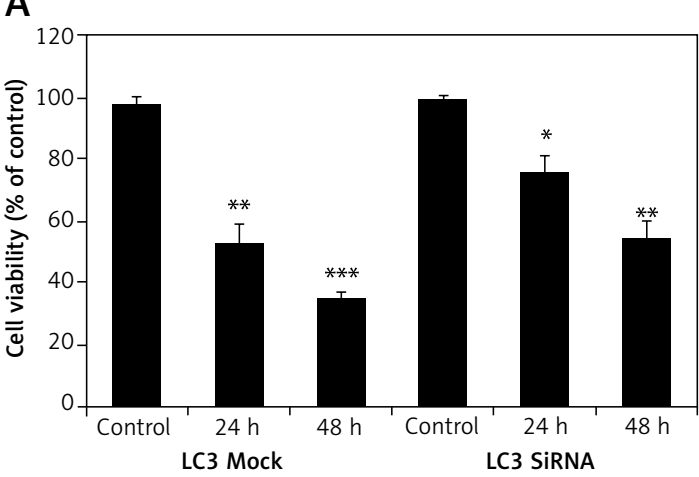

B
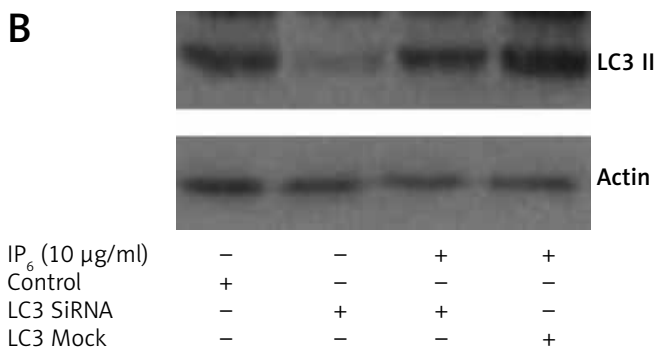

Figure 5. Inositol-6 phosphate $\left(\mathrm{IP}_{6}\right)$-induced cell death mediated by LC3-II. A - IP- - mediated cytotoxicity was analyzed in HT-29 siRNA-mock (siRNA control) and siRNA-LC3 cells by an MTT assay. B - The expression of LC3-II was analyzed in HT-29 siRNA mock and siRNA-LC3 cells by western blotting The statistical significance at ${ }^{*} p<0.05,{ }^{* *} p<0.01$ and ${ }^{* * *} p<0.0001$.

As shown in Figure $4 \mathrm{~A}, \mathrm{IP}_{6}$ treatment increased AO staining in acidic vesicular organelles in HT-29 in a time-dependent manner. At $10 \mu \mathrm{g} / \mathrm{ml} \mathrm{IP}$, the number of AO-stained cells increased dramatically when compared to that of control cells. When these IP $\mathrm{P}_{6}$-treated cells were examined under a transmission electron microscope, double- or multi-membrane structures containing high-electron-density substances characteristic of autophagosomes and autolysosomes were present (Figure 3 B). Many autolysosomes were degraded in cells treated with $10 \mu \mathrm{g} / \mathrm{ml} \mathrm{IP}_{6}$ for 24 and $48 \mathrm{~h}$ (Figure $3 \mathrm{~B}$ ).

\section{Inositol-6 phosphate activates LC3-II} and Beclin 1 in HT-29 colon cancer cells

It is known that the Beclin 1 level and LC3 conversion (LC3-I to LC3-II) are selective markers of autophagy [22]. As shown in Figure $4 \mathrm{C}, \mathrm{IP}_{6}$ treatment markedly increased the expression of Beclin 1 and LC3-II, suggestive of autophagy induction. To further confirm the induction of autophagy by $\mathrm{IP}_{6}$, we utilized fluorescence microscopy to examine autophagosome formation in HT-29 cells. The conversion of LC3-I (a soluble form) to LC3-II (a lipidized form) is associated with the membranes of autophagosomes [23] and can be detected by the formation of punctate structures. Treatment of cells
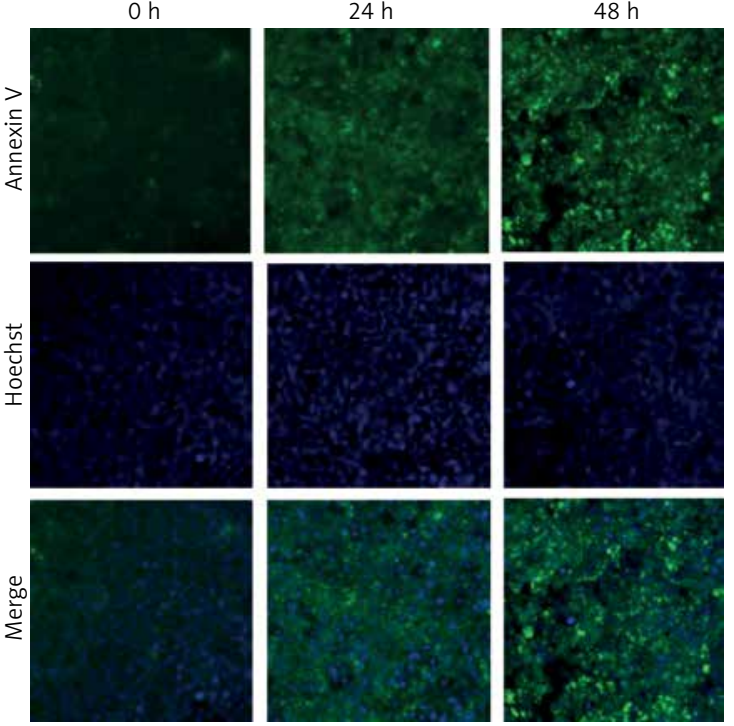

Figure 6. Inositol-6 phosphate (IP $)$ increased the expression of annexin V-FITC. Cells were inoculated in a 96-well plate and treated with $\mathrm{P}_{6}$ for 24 and $48 \mathrm{~h}$. The detailed methodology is described in the Material and methods section. Inositol- 6 phosphate increased the expression of annexin $\mathrm{V}$ in a time-dependent manner. Annexin $V$ was attached to FITC (green) and the cells were counter-stained with Hoechst (blue) to detect nuclei (20x magnification)

for $24 \mathrm{~h}$ and $48 \mathrm{~h}$ with $\mathrm{IP}_{6}$ resulted in increased expression of LC3-II in HT-29 colon cancer cells (Figure $4 \mathrm{D}$ ). These findings clearly indicated that $\mathrm{IP}_{6}$ induces autophagy by activating the expression of LC3-II in HT-29 colon cancer cells.

\section{Inositol-6 phosphate-induced cell death is mediated by LC3-II}

$\mathrm{IP}_{6}$-mediated cell viability was observed in HT-29 Mock (Mock SiRNA control) and siRNA-LC3 cells. LC3 silencing prevented IP I $_{6}$ induced HT-29 cell death (Figure 5 A). In HT-29 SiRNA mock cells, IP-induced LC3A expression was blocked (Figure 5 B). These results confirmed that $\mathrm{IP}_{6}$-induced cell death in HT-29 was mediated by the activation of LC3-II.

\section{Inositol-6 phosphateinduces apoptosis in HT-29 colon cancer cells}

If a natural/synthetic drug source can induce apoptosis, it can be developed as a chemotherapeutic agent [5, 24, 25]. As shown in Figure 6, treatment with $\mathbb{I P}_{6}$ resulted in an increase in the cell population that was positive for annexin V-FITC staining. Starting at 24-48 h, HT-29 cells underwent apoptosis, as detected by the green fluorescence of annexin V-FITC when compared 
with that of control cells (Figure 6). Hence, we confirmed that $\mathrm{IP}_{6}$ induces apoptosis, as evidenced by the increased amount of exposed phosphatidylserine.

\section{Discussion}

Abundant evidence indicates that autophagy plays a vital role in determining cell fate. When subjected to miscellaneous stresses, tumor cells initiate autophagy; nevertheless, the excessive activation of autophagy appears to result in cell death. In our study, we first observed that $I_{6}$ at a concentration of 2.5 to $20 \mu \mathrm{g} / \mathrm{ml}$ dose-dependently inhibits the viability of HT-29 colon cancer cells (Figure 1). It is well known that most chemotherapeutic agents are toxic not only to tumor cells, but also to normal cells; thus, these agents produce major side effects. The selective cytotoxicity of $\mathrm{I}_{6}$ against colon cancer cells makes it an attractive candidate for drug development.

mTORC1 plays a key role in protein synthesis regulation via its effectors S6K1 and 4E-BP1. Constitutively activated mTOR signaling has been shown previously in CRC [26]. Indeed, several ribosomal proteins are up-regulated in CRC, including the S6K1 target S6 [27]. Targeted mTOR inhibition decreases adenoma formation in a mouse familial adenomatous polyposis model [28] and also inhibits CRC cell growth. It is also well known that the inhibition of mTOR signaling in CRC activates autophagy [16]. In the present study, we showed that IP inhibits downstream effectors of mTORC1, i.e., P70-S6K1 and 4E-BP1 (Figure 3). Deletion of P70-S6K1 in mice results in defective ribosomal biogenesis and the disruption of a single ribosomal protein shuts down ribosomal synthesis [29]. We confirmed that $\mathrm{IP}_{6}$ inhibits Akt/mTOR signaling in HT-29 colon cancer cells.

mTOR negatively regulates autophagy, and therefore we assessed the effects of IP on autophagy [29, 30]. Autophagy is a physiological process that allows the degradation of cytoplasmic contents, including unfolded proteins and membranous organelles, under certain stress conditions. This functions as a temporary survival mechanism for cells. Certain cellular stresses, such as oxidative stress, nutrient starvation, misfolded protein accumulation, and irradiation, could induce autophagy. Once initiated, the process delivers cytoplasmic materials to lysosomes via double membrane organelles termed autophagosomes, which enclose a portion of the cytoplasm and intracellular organelles [31]. However, recent studies have shown that autophagy is also a cell death mechanism and is a response to various anticancer therapies in many kinds of cancer cells [32, 33]. Our results showed that IP $\mathrm{P}_{6}$ induces autophagy, as confirmed by the increased expression of LC3-II and Beclin 1 (Figure 4).
LC3 is a commonly used autophagy marker, and its processed form, LC3-I, resides in the cytoplasm. After autophagy induction, LC3-II, the conjugated form of LC3, associates with autophagosomes. However, an increase in autophagosomes alone, suggested by increased LC3-II levels, does not necessarily indicate increased autophagy [34].

We also confirmed that $\mathrm{IP}_{6}$ induces apoptosis, based on the increased expression of annexin $\mathrm{V}$ (Figure 6). Apoptosis is characterized by cell shrinkage, chromatin condensation, DNA fragmentation, and the activation of specific cysteine proteases known as caspases. We previously showed that rice bran $\mathrm{IP}_{6}$ induces apoptosis by regulating pro- and anti-apoptotic Bax and Bcl-xl, as well as via the activation of caspase- 3 and -8 $[35,36]$. Inositol- 6 phosphate can also induce mitochondrial-mediated apoptosis in HT-29 cells.

In conclusion, the Akt/mTOR pathway plays an essential role in the survival of colon cancer cells. We demonstrated that $\mathrm{IP}_{6}$ inhibits the Akt/mTOR signaling pathway in HT-29 cells. We previously showed that $\mathrm{IP}_{6}$ induces apoptosis in colon cancer cells. In this study, we further elucidated the mechanism by which $\mathrm{IP}_{6}$ causes autophagy, i.e., by activating the expression of LC3-II and Beclin 1. We therefore suggest that $\mathrm{IP}_{6}$ has the potential to be developed as an anti-cancer remedy.

\section{Acknowledgments}

Dr. Norhaizan greatly acknowledges the Fundamental Research Grant Scheme (FRGS), Malaysia (Grant Number: 5524455) for financial assistance. The authors would like to extend their sincere appreciation to the Deanship of Scientific Research at King Saud University for funding this work (Research Group No. RG-1435-057).

\section{Conflict of interest}

The authors declare no conflict of interest.

\section{References}

1. Huerta S, Goulet EJ, Livingston EH. Colon cancer and apoptosis. Am J Surg 2006; 191: 517-26.

2. Sheng WY, Yong Z, Yun Z, Hong H, Hai LL. Toll-like receptor 4 gene polymorphisms and susceptibility to colorectal cancer: a meta-analysis and review. Arch Med Sci 2015; 11: 699-707.

3. Pandurangan AK, Esa NM. Dietary non-nutritive factors in targeting of regulatory molecules in colorectal cancer: an update. Asian Pac J Cancer Prev 2013; 14: 5543-52.

4. Pandurangan AK, Dharmalingam P, Sadagopan SK, Ganapasam S. Luteolin inhibits matrix metalloproteinase 9 and 2 in azoxymethane-induced colon carcinogenesis. Hum Exp Toxicol 2014; 33: 1176-85.

5. Saadatdoust Z, Pandurangan AK, Ananda Sadagopan SK, Mohd Esa N, Ismail A, Mustafa MR. Dietary cocoa inhibits colitis associated cancer: a crucial involvement of the IL-6/ STAT3 pathway. J Nutr Biochem 2015; 26: 1547-58. 
6. Ananda Sadagopan SK, Mohebali N, Looi CY, et al. Forkhead Box Transcription Factor (FOXO3a) mediates the cytotoxic effect of vernodalin in vitro and inhibits the breast tumor growth in vivo. J Exp Clin Cancer Res 2015; 34: 147

7. Wu D, Yao Q, Chen Y, Hu X, Qing C, Qiu M. The in vitro and in vivo antitumor activities of tetracyclic triterpenoids compounds actein and 26-deoxyactein isolated from rhizome of cimicifuga foetida L. Molecules 2016; 21: E1001.

8. Lai YJ, Tai CJ, Wang CW, et al. Anti-cancer activity of solanum nigrum (AESN) through suppression of mitochondrial function and epithelial-mesenchymal transition (EMT) in breast cancer cells. Molecules 2016; 21 : E553.

9. Jariwalla RJ. Rice-bran products: phytonutrients with potential applications in preventive and clinical medicine. Drugs Exp Clin Res 2001; 27: 17-26.

10. Shamsuddin AM. Anti-cancer function of phytic acid. Int J Food Sci Technol 2002; 37: 769-82.

11. Norazalina S, Norhaizan ME, Hairuszah I, Norashareena MS Anticarcinogenic efficacy of phytic acid extracted from rice bran on azoxymethane-induced colon carcinogenesis in rats. Exp Toxicol Pathol 2010; 62: 259-68.

12. Nurul-Husna S, Norhaizan ME, Hairuszah I, Abdah MA Norazalina S, Norsharina I. Rice bran phytic acid (IP6) induces growth inhibition, cell cycle arrest and apoptosis on human colorectal adenocarcinoma cells. J Med Plants Res 2010; 4: 2283-9.

13. Norazalina S, Norhaizan ME, Hairuszah I, Sabariah AR, Husna SN, Norsharina I. Antiproliferation and apoptosis induction of phytic acid in hepatocellular carcinoma (HEPG 2) cell lines. Afr J Biotechnol 2011; 10: 16646-53.

14. Wani ZA, Guru SK, Rao AV, et al. A novel quinazolinone chalcone derivative induces mitochondrial dependent apoptosis and inhibits PI3K/Akt/mTOR signaling pathway in human colon cancer HCT-116 cells. Food Chem Toxicol 2016; 87: 1-11.

15. Wee LH, Morad NA, Aan GJ, Makpol S, Wan Ngah WZ, Mohd Yusof YA. Mechanism of chemoprevention against colon cancer cells using combined gelam honey and ginger extract via mTOR and Wnt/beta-catenin pathways. Asian Pac J Cancer Prev 2015; 16: 6549-56.

16. Din FV, Valanciute A, Houde VP, et al. Aspirin inhibits mTOR signaling, activates AMP-activated protein kinase, and induces autophagy in colorectal cancer cells. Gastroenterology 2012; 142: 1504-15.e3.

17. Lin L, Baehrecke EH. Autophagy, cell death, and cancer Mol Cell Oncol 2015; 2: e985913.

18. Chan WY, Huang H, Tam SC. Receptor-mediated endocytosis of trichosanthin in choriocarcinoma cells. Toxicology 2003; 186: 191-203.

19. Pandurangan AK, Dharmalingam P, Sadagopan SK, Ramar M, Munusamy A, Ganapasam S. Luteolin induces growth arrest in colon cancer cells through involvement of Wnt/ beta-catenin/GSK-3beta signaling. J Environ Pathol Toxicol Oncol 2013; 32: 131-9.

20. Guertin DA, Sabatini DM. Defining the role of mTOR in cancer. Cancer Cell 2007; 12: 9-22.

21. Pullen N, Thomas G. The modular phosphorylation and activation of p70s6k. FEBS Lett 1997; 410: 78-82.

22. Towers CG, Thorburn A. Therapeutic targeting of autophagy. EBioMedicine 2016; 14: 15-23.

23. Klionsky DJ, Abeliovich H, Agostinis P, et al. Guidelines for the use and interpretation of assays for monitoring autophagy in higher eukaryotes. Autophagy 2008; 4: 151-75.
24. Zhang C, Yu H, Shen Y, Ni X, Shen S, Das UN. Polyunsaturated fatty acids trigger apoptosis of colon cancer cells through a mitochondrial pathway. Arch Med Sci 2015; 11: 1081-94.

25. Irani S, Shahmirani Z, Atyabi SM, Mirpoor S. Induc tion of growth arrest in colorectal cancer cells by cold plasma and gold nanoparticles. Arch Med Sci 2015; 11 : 1286-95.

26. Lai MD, Xu J. Ribosomal proteins and colorectal cancer. Curr Genomics 2007; 8: 43-9.

27. Pandurangan AK. Potential targets for prevention of colorectal cancer: a focus on PI3K/Akt/mTOR and Wnt pathways. Asian Pac J Cancer Prev 2013; 14: 2201-5.

28. Fujishita T, Aoki K, Lane HA, Aoki M, Taketo MM. Inhibition of the mTORC1 pathway suppresses intestinal polyp formation and reduces mortality in ApcDelta716 mice. Proc Natl Acad Sci U S A 2008; 105: 13544-9.

29. Din FV, Valanciute A, Houde VP, et al. Aspirin inhibits mTOR signaling, activates AMP-activated protein kinase, and induces autophagy in colorectal cancer cells. Gastroenterology 2012; 142: 1504-15.e3.

30. Wu J, Hu G, Dong Y, et al. Matrine induces Akt/mTOR sig nalling inhibition-mediated autophagy and apoptosis in acute myeloid leukaemia cells. J Cell Mol Med 2017; 21 . 1171-81.

31. Parkhitko AA, Favorova OO, Henske EP. Autophagy: mechanisms, regulation, and its role in tumorigenesis. Biochemistry (Mosc) 2013; 78: 355-67.

32. Suh Y, Afaq F, Khan N, Johnson JJ, Khusro FH, Mukhtar H. Fisetin induces autophagic cell death through suppression of mTOR signaling pathway in prostate cancer cells. Carcinogenesis 2010; 31: 1424-33.

33. Lee Y, Sung B, Kang YJ, et al. Apigenin-induced apoptosis is enhanced by inhibition of autophagy formation in HCT116 human colon cancer cells. Int J Oncol 2014; 44: 1599-606.

34. Mizushima N, Yoshimori T, Levine B. Methods in mammalian autophagy research. Cell 2010; 140: 313-26.

35. Shafie NH, Esa NM, Ithnin H, Saad N, Pandurangan AK. Pro-apoptotic effect of rice bran inositol hexaphosphate (IP6) on HT-29 colorectal cancer cells. Int J Mol Sci 2013; 14: 23545-58.

36. Shafie NH, Mohd Esa N, Ithnin H, Md Akim A, Saad N, Pandurangan AK. Preventive inositol hexaphosphate extracted from rice bran inhibits colorectal cancer through involvement of Wnt/beta-catenin and COX-2 pathways. Biomed Res Int 2013; 2013: 681027. 